\title{
Penerapan Arsitektur Metafora Pada Bangunan Pusat MOdE DI Kota SURAKARTa
}

\author{
Leoni N. Damarani ${ }^{1 *}$, Widi Suroto ${ }^{2}$, Tri Yuni Iswati ${ }^{3}$ \\ Program Studi Arsitektur, Fakultas Teknik, Universitas Sebelas Maret Surakarta ${ }^{1}$ \\ E-mail : leonidamarani@gmail.com* \\ Program Studi Arsitektur, Fakultas Teknik, Universitas Sebelas Maret Surakarta ${ }^{2}$ \\ Program Studi Arsitektur, Fakultas Teknik, Universitas Sebelas Maret Surakarta ${ }^{3}$
}

\begin{abstract}
Metaphorical architecture is the way to understand something by comparing them with some familiar ideas or objects, so it gains a better perception. The application of Metaphorical Architecture in Fashion Center Building serves to bring up the image of activities performed inside the building through borrowing some concrete things inside it as a visualization of the forms in fashion to attract visitors, while the abstracts forms are to be function to create some atmosphere inside the building to reinforce the first impression and some fashion's characteristics in it.

In view years, mode has grown enormously. Fashion that initially served as a basic needs of human being, has now evolved into one of the necessities to show the social identity of society. Surakarta has some potential part in developing fashion availability which is supported by the availability of various kind of Batik which has been known in the world wide. Many of fashion activities has done by Surakarta's Government started in 2008 and will be growing till 20 years ahead. The number of actors fashion has been increasing by this 10 years and not balanced with the availability of fashion mode facilities.
\end{abstract}

Keywords: fashion mode, metaphorical architecture, surakarta

\section{PENDAHULUAN}

Mode pada masa kini telah mengalami perkembangan pesat khusunya di kota Surakarta. Mode sendiri berkaitan dengan seni yang didalamnya dapat menginterpretasikan suatu hal. Pusat Mode direncanakan sebagai bangunan komersil yang didalamnya menaungi seluruh kegiatan bermode dan terdiri dari beberapa pelaku sehingga mampu menjadi suatu ikon untuk menarik pengunjung yang datang sehingga dapat menikmati kegiatan mode didalamnya. Untuk itu, digunakan suatu metode pendekatan penyelesaian desain yaitu Arsitektur Metafora. Arsitektur Metafora dipilih dengan pertimbangan karena merupakan suatu cara untuk memahami suatu hal dimana hal tersebut dipahami menjadi hal yang lain sehingga mendapatkan pemahaman yang lebih baik. Dan Arsitektur Metafora dalam penuangan idenya dapat berupa bentuk visual dan non- visual sehingga mudah ditangkap dan dirasakan maknanya oleh orang yang melihat.

Penerapan Arsitektur Metafora dalam bangunan Pusat Mode disesuaikan berdasar teori Metafora Kombinasi, yaitu penerapan Abstrak dan Konkrit sesuai dengan peminjaman bentuk dari jenis mode dan juga sifat - sifat mode. Dari segi visual / konkrit, Arsitektur metafora digunakan sebagai pembentuk kesan objek untuk menarik minat pengunjung dan interpretasi terhadap kegiatan didalamnya. Sedangkan, sebagai pembentuk kesan dan suasana akan ditekankan pada penerapan Arsitektur Metafora abstrak. Sehingga, dalam penerapan pendekatan Pusat Mode di kota Surakarta ini menggunakan Arsitektur Metafora Kombinasi. (Antoniades, A. C. (1990). Poetic of Architecture: Theory of Design. New York: Van Nostrand Reinhold.) 
Tidak dapat dipungkiri, pada dasarnya mode yang telah berkembang pesat merupakan kebutuhan pokok manusia. Dengan perkembangan zaman, mode tidak lagi sekedar kebutuhan pokok namun juga menjadi penunjuk identitas dan status sosial seseorang. Perkembangan zaman akan mempengaruhi pandangan masyarakat didalamnya terhadap keberadaan mode. Derajat sosial seseorang akan terlihat dari cara orang berpakaian sehingga memungkinkan untuk bereskpresi agar dapat mencocokkan dirinya pada golongan masyarakat tertentu. (Charlotte, Ph. D, Fair Child Dictionary of Fashion, Fair Child Publication, New York).

Kota Surakarta, yang biasa akrab disebut kota Solo, memiliki potensi besar dalam dunia mode. Menurut Departemen Perindustrian dan Perdagangan Surakarta, kota Surakarta menjadi salah satu pusat bahan mode selain Semarang dan Yogyakarta, karena 60\% bahan tekstil berasal dari Solo dan batik Solo telah terkenal mencapai kancah nasional hingga internasional.

Selain itu, beberapa fasilitas mode dan acara seputar mode baik yang diadakan oleh Pemerintah Kota Surakarta ataupun oleh produsen dan penikmat mode selalu ramai didatangi oleh masyarakat.

Jumlah penikmat mode untuk selalu mengikuti karya busana terbaru terlihat dari adanya peningkatan permintaan produksi mode dalam jangka waktu 20 tahun terakhir. Pengunjung acara mode selalu meningkat sekitar $20-50$ orang setiap tahun, berasal dari anak - anak hingga dewasa (Wijaya, 2016).

Produsen mode atau perancang busana Indonesia sendiri berasal $40 \%$ dari kota Surakarta. Namun produsen mode di kota Surakarta masih mengalami kesulitasn fasilitas karena belum terdapat fasilitas yang menaungi seluruh kegiatan bidang mode dalam satu tempat tertentu.
Peningkatan jumlah peminat busana tersebut membuktikan adanya tren yang positif terhadap apresiasi perkembangan busana hingga masyarakat selalu ingin mengikuti setiap perkembangannya.

Oleh karena itu menanggapi adanya permintaan yang tinggi terhadap kegiatan dan ketersediaan mode di kota Surakarta maka diperlukan wadah yang dapat melingkupi kegiatan mode mulai dari kegiatan produksi hingga penunjangnya.

Perencanaan perancangan Pusat Mode akan menjadi objek yang menaungi seluruh kegiatan mode didalamnya, mulai dari kegiatan utama berupa produksi sehingga kegiatan produksi karya busana mulai dari proses desain, jahit dan bordir hingga finishing dapat diwadahi berdasarkan kebutuhan yang ada dalam satu tempat tertentu. Kegiatan penunjang lainnya juga dapat dinaungi mendukung kegiatan produksi sehingga produsen dapat memamerkan dan mempromosikan karya busana yang dihasilkan. Selain itu, pengunjung dapat menikmati karya busana yang terfokus dalam satu wadah sekaligus.

\section{METODE}

Metode pendekatan desain meggunakan metode Arsitektur Metafora. Arsitektur Metafora dapat diidentifikasikan menjadi tiga macam, yaitu Metafora abstrak (intangible metaphor), peminjaman bentuk melalui ide, kondisi atau kualitas tertentu. Metafora konkrit (tangible metaphor), peminjaman bentuk dengan tegas dari karakter visual yang ada. Metafora kombinasi (combined metaphor), gabungan antara bentuk abstrak dan konkrit. (Antoniades, 1990, hal. $30-31$ ).

Dari teori yang digunakan terkait dengan Arsitektur Metafora tersebut akan menghasilkan suatu rumusan untuk proses perencanaan dan perancangan Pusat Mode di Kota Surakarta yang dimetaforakan berupa peminjaman bentuk bahan dasar mode seperti kain 
dan jenis mode serta sifat dan karakter mode. Metafora akan diterapkan pada :

- Tapak

Meliputi pemilihan tapak yang mampu mewakili kemudahan akses yang fleksibel dan mudah dikenali

- Ruang dan Bentuk

Penerapan Arsitektur Metafora pada ruang dan bentuk terkait dengan karakteristik yang menarik, dinamis serta variatif sebagai inspirasi desain untuk menyalurkan interpretasi fungsi bangunan dengan tampilan bangunan.

\section{- $\quad$ Struktur dan Utilitas}

Untuk mendukung bentuk yang dirancang maka perlu tunjangan struktur dan utilitas sehingga bentuk lebih ekspresif.

Sedangkan, metode desain yang digunakan dalam proses perencanaan dan perancangan Pusat Mode adalah metode apresiatif atau deskriptif kualitatif, yang didalamnya meliputi 3 aspek, yaitu tahap ide, tahap transformasi dan tahap fisik produk.

Tahap ide merupakan tahapan awal yang merupakan pemberangkatan ide untuk menggali potensi terkait dengan obyek untuk menentukan gagasan awal. Setelah itu dilakukan tahap transformasi yang merupakan tahap survey lapangan pada lokasi tapak di jalan Slamet Riyadi. Setelah data terkait didapatkan maka dilanjutkan dengan tahapan analisis mulai dari analisis ruang, analisis tapak, analisis struktur dan analisis bentuk. Serta tahapan terakhir yaitu tahapan fisik produk berdasarkan penerapan arsitektur metafora ke dalam bangunan Pusat Mode.

\section{Hasil dan Pembahasan}

\subsection{Peruangan}

Penerapan Arsitektur Metafora pada bangunan Pusat Mode di kota Surakarta terdapat pada beberapa bagian, yaitu peruangan. Perencanaan ruang berdasar Arsitektur Metafora Kombinasi dibedakan menjadi dua, yaitu secara abstrak dan konkrit.
Arsitektur Metafora konkrit dalam ruang kegiatan disesuaikan berdasar peminjaman bentuk dari kain yang merupakan bahan dasar pakaian dengan karakteristik fleksibel. Hal ini kemudian menjadikan inspirasi bentuk muncul dalam peruangan kegiatan baik utama dan penunjang.

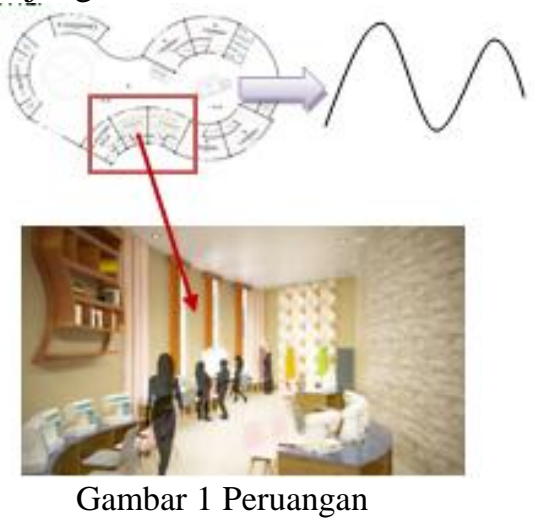

Dengan aplikasi bentuk yang fleksibel memudahkan juga akses didalam ruang menjadi lebih fleksibel. Selain itu dengan Arsitektur Metafora Abstrak diaplikasikan penggunaan material dengan permainan halus dan kasar yaitu menggunakan warna - warna soft yaitu cream dan juga warna untuk memunculkan semangat dalam proses produksi, yaitu orange.

(Mahnke, Frank. H, Mahnke, Rudolf H. 1993. Color and Light in Man Made Environment. New York. Van Nostrand Reinhold).

\subsection{Perencanaan Tapak}

Pemilihan Tapak

Pemilihan tapak didasarkan pada beberapa kriteria yang ditetapkan. Dasar pertimbangan pemilihan tapak yaitu sesuai dengan perencanaan pengembangan wilayah Kota Surakarta berdasar RTRW yang berlaku tahun $2011-2031$.

Selain itu, terletak pada lokasi yang strategis yang mampu memberikan akses mudah bagi pengunjung sampai ke pusat mode dan dilalui oleh banyak orang. Akses dapat dicapai oleh kendaraan dan pejalan kaki serta berdekatan dengan beberapa bangunan yang dapat mendukung Pusat Mode. 


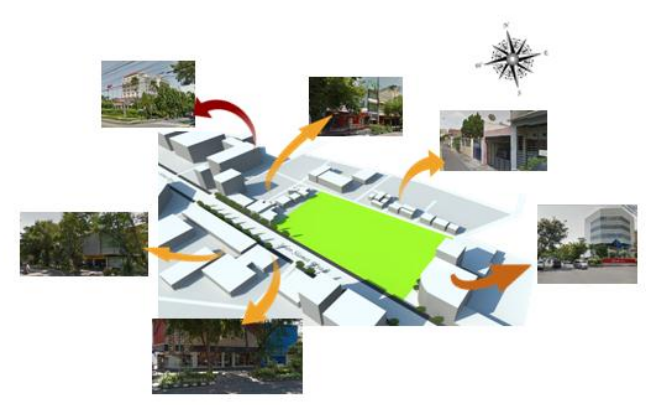

Gambar 2. Tapak Terpilih

Luasan tapak yang terpilih adalah 16.000 $\mathrm{m}^{2}$. Sesuai gambar 1 tapak terpilih berada di Jalan Slamet Riyadi yang di bagian selatan berbatasan dengan jalan Slamet Riyadi, sebelah utara berbatasan dengan pemukiman warga, sebelah timur berbatasan dengan Jalan KH Ahmad Dahlan dan beberapa bangunan perkantoran serta bagian barat dengan ruko dan bangunan hotel.

\section{Pencapaian}

Letak tapak terpilih bangunan Pusat Mode berbatasan langsung dengan jalan utama kota Surakarta yaitu jalan Slamet Riyadi sehingga memberikan potensi untuk kemudahan akses pengunjung menuju ke bangunan. Potensi ini memerlukan analisis untuk nantinya dimanfaatkan sebagai perletakan Main Entrance bangunan sehingga bangunan yang direncanakan berdasarkan potensi jalan di sekitar tapak tersebut memiliki kemudahan untuk dikenali dan mudah dicapai pengunjung serta mendukung fungsi kegiatan sebagai pusat mode.

Terpilih main entrance di Jalan Slamet Riyadi berupa in entrance and out entrance. Penggunaan system masuk dan keluar berada di jalan Slamet Riyadi dengan tujuan memudahkan akses bagi pengunjung dan pengguna lainnya sehingga kembali lagi menuju jalan utama. Penggunaan satu system ini difungsikan juga untuk kemudahan pengamanan bangunan.

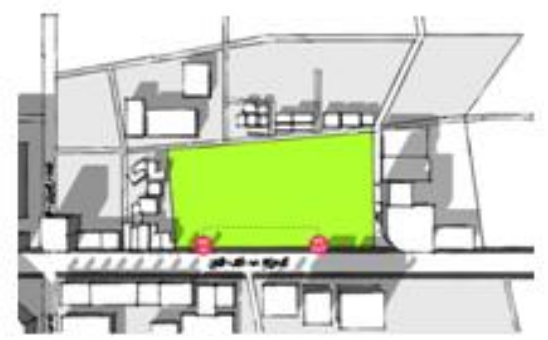

Gambar 3. Hasil Analisis Pencapaian

View dan Orientasi

Letak tapak yang berada di tepi jalan dan berbatasan dengan beberapa bangunan disekitarnya memberikan potensi bagi fungsi kegiatan dan pendekatan metafora yang dipilih untuk pemanfaatan view dan orientasi yang tersedia.

Karena letak tapak bangunan berada di jalan Slamet Riyadi dan jalan KH Ahmad Dahlan maka berdasar entrance dan kebutuhan view serta kemudahan akses maka orientasi diletakkan menuju bagian selatan sehingga dapat dinikmati oleh pengamat dan menangkap perhatian pengamat sesuai citra yang ingin ditampilkan sesuai Arsitektur Metafora pada bangunan Pusat Mode.

Letak tapak berada di simpang tiga jalan, maka orientasi bangunan memiliki tiga muka agar metafora dapat dinikmati dari berbagai sisi dimana intensitas pengamat di setiap sisi tersebut tinggi. Tampilan bangunan difokuskan pula untuk ditonjolkan di tiga sisi bangunan yang merupakan jalan dan sudut dengan intensitas tinggi untuk dilalui dan diamati orang.

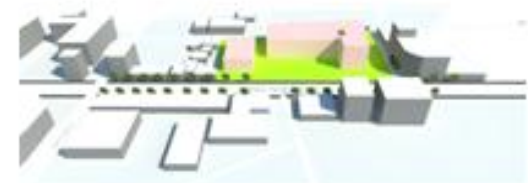

Gambar 4. Hasil Analisis View dan Orientasi

\subsection{Perencanaan Struktur dan Utilitas}

Penerapan Arsitektur Metafora pada bangunan Pusat Mode membutuhkan suatu bentuk yang menarik sehingga dibutuhkan suatu struktur yang dapat 
menaungi bentuk yang ditimbulkan dari penggunaan Arsitektur Metafora sesuai dengan peminjaman bentuk yang digunakan.

Sub structure bangunan menggunakan pondasi setempat dengan pertimbangan ketinggian bangunan hanya 3 lantai. Upper structure menggunakan rigid frame pada sebagain besar ruang karena tidak memerlukan sifat khusus dengan adanya keberadaan kolom. Super structure menggunakan atap spaceframe, dan atap dak dengan tujuan pemanfaatan bentuk dinamis sesuai dengan arsitektur metafora yang diterapkan.

Utilitas yang diterapkan pada bagian atap yang berbentuk dinamis dengan spaceframe yaitu menggunakan peletakan talang di bagian atap dan disalurkan menuju ruang utilitas dan pipa serta disalurkan menuju halaman bangunan sehingga air hujan dapat mengalir keluar bangunan.

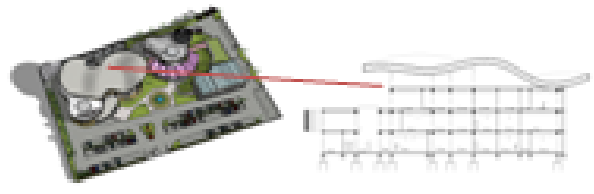

Gambar 5. Hasil Analisis Struktur dan Utilitas

\subsection{Perancangan Bentuk Sesuai Arsitektur} Metafora

Tata massa bangunan Pusat Mode disesuaikan dengan keadaan tapak yang relatif datar dan kebutuhan ruang untuk kegiatang jamak (multifungsi) sehingga dapat dikembangan dengan penggunaan tata massa jamak.

Bentuk bangunan Pusat Mode disesuaikan dengan pendekatan yang digunakan yaitu Arsitektur Metafora dengan jenis Metafora Kombinasi yaitu memadukan metafora konkrit dan abstrak.

A. Arsitektur Metafora Konkrit

Peminjaman bentuk Arsitektur Metafora Konkrit pada bangunan Pusat Mode berawal dari komponen utama dari sebuah mode yaitu kain. Kain memiliki karakter yang dinamis sehingga bentuk kain diadopsi untuk penyusunan bangunan Pusat Mode secara fisik. Hal ini terlihat pada bentuk atap bangunan yang cenderung bergelombang dan lengkung sesuai bentuk kain (Gambar 6). Sedangkan, kain akan diproses menjadi beberapa karya busana yang salah satunya adalah rok. Bentuk rok yang bergelombang dan dinamis ini dimanfaatkan untuk bentuk atap pada bangunan penunjang Pusat Mode. (Gambar 7).

Sehingga aplikasi Arsitektur Metafora Konkrit dalam bangunan Pusat Mode memberikan konfigurasi bentuk yang dinamis. (Gambar 8).

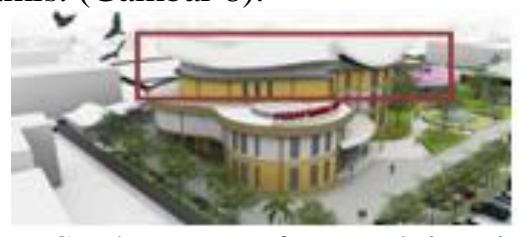

Gambar 6. Metafora Konkrit Kain

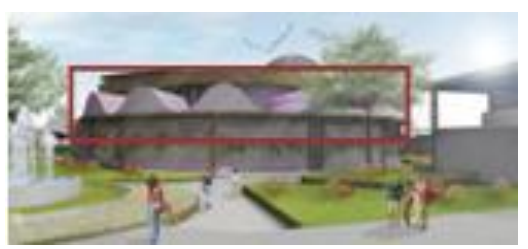

Gambar 7. Metafora Konkrit Rok

Menciptakan karakter yang dinamis pada konfigurasi massa bangunan sesuai dengan metafora kain dan sifat mode.

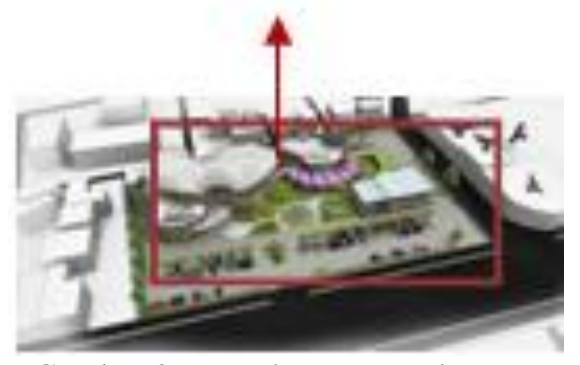

Gambar 8. Bentuk Pusat Mode

B. Arsitektur Metafora Abstrak

Arsitektur Metafora Abstrak pada bangunan berasal dari peminjaman bentuk berdasar karakter dari mode yang selalu mengikuti zaman dan tidak pernah berhenti pada suatu titik tertentu (Owen Joe, 2015). Sehingga bentuk abstrak ditampilkan melalui karakter yang selalu mengalir dan dinamis, hal ini terlihat dalam eksterior dan 
interior bangunan. Pada interior bangunan, ruang yang tercipta memiliki nuansa yang selalu mengalir dengan penggunaan ruang - ruang lengkung pada beberapa bagian. (Gambar 9).

Nuansa kental dengan mode diperlihatkan dengan penggunaan material halus dan kasar serta pemilihan warna yang menggunakan warna - warna mode seperti putih, pink, dan ungu. Dalam proses pembuatan mode diaplikasikan juga warna orange untuk membangkitkan semangat dalam bermode. (Gambar 10). (Wright, Angela. 2008. Psychological Properties of Colours, Colour Affect. )

Selain itu, juga dengan efek alunan musik menambah suasana bermode menjadi lebih terasa dan efek pencahayaan pada beberapa ruangan sebagai pembentukan karakter yang romantis.
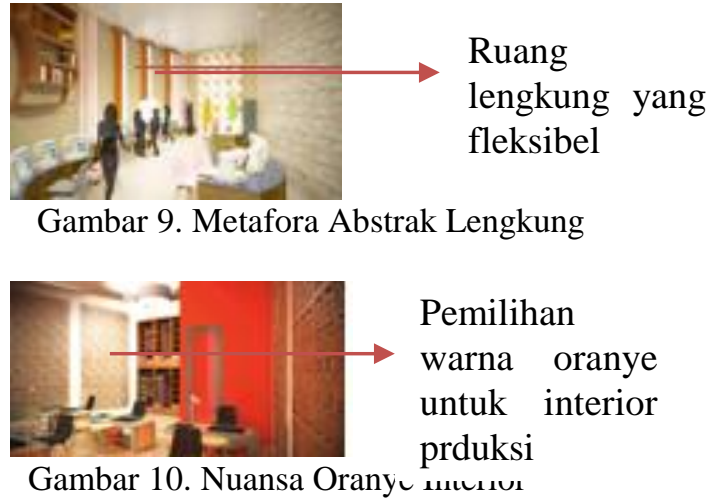

\section{KESIMPULAN}

Penerapan metafora dalam perancangan bangunan Pusat Mode di Kota Surakarta diperlukan adanya suatu proses untuk fokus terhadap kegiatan utama terlebih dahulu, yaitu kegiatan produksi. Kegiatan produksi ini merupakan kegiatan inti didalam menghasilkan suatu mode dan terdiri dari beberapa pelaku dari produsen hingga pengunjung. Dalam kegiatan utama tersebut bentuk metafora akan diterapkan sesuai dengan fungsi bangunan sehingga dapat dengan mudah dikenali pengamat dan menarik perhatian pengunjung.

Selain itu, kegiatan dalam bangunan penunjang juga menjadi perhatian dalam diterapkannya metafora dengan tetap memakai bentuk yang dinamis sesuai peminjaman bentuknya. Kondisi sekitar tapak juga perlu mendapat perhatian dalam proses desain sehingga desain yang dihasilkan dapat sinergis dengan bangunan disekitarnya dan metafora yang diterapkan dapat didukung dari tapak yang terpilih.

\section{REFERENSI}

Antoniades, A. C. (1990). Poetic of Architecture: Theory of Design. New York: Van Nostrand Reinhold.

Charlotte, Ph. D, Fair Child Dictionary of Fashion, Fair Child Publication, New York

Mahnke, Frank. H, Mahnke, Rudolf H. 1993. Color and Light in Man Made Environment. New York. Van Nostrand Reinhold.

Joe, Owen. 2015. Sifat - Sifat Mode.

Peraturan Daerah Kota Surakarta Nomor 8 Tahun 2009 Tentang Bangunan

Wijaya, Miko. 2016. Data Peserta SBC 2008-2016.

Wright, Angela. 2008. Psychological Properties of Colours, Colour Affect. 